\title{
LAS FIGURAS PROTECTORAS Y SU EFECTO POLÍTICO. REYES Y DAIMONES: LAS MARCAS DE LA CUSTODIA
}

\author{
Maria Cecília Colombani ${ }^{1}$
}

\begin{abstract}
Resumen
El objetivo de este artículo es analizar las figuras protectoras que se encuentran presentes en Teogonía y Trabajos y dias. De ellas hemos escogido al rey, como garante del orden y la justicia emanada de Zeus, y a los daimones, vigilantes invisibles de los hombres. Para ello utilizaremos los conceptos de lo Mismo y lo Otro, encarnados en linajes diurnos y nocturnos, a fin de subrayar las características asociadas a estas figuras que se traducen a nivel textual en adjetivos y verbos específicos. Asimismo, veremos cómo afectan el equilibrio político de la ciudad.
\end{abstract}

\section{Palabras clave}

Protección; vigilancia; rey; daimon; Hesíodo; política.

\section{Resumo}

O objetivo deste artigo é analisar as figuras protetoras presentes na Teogonia e em Os trabalhos e os dias. Delas, escolhemos a figura do rei, como garante da ordem e da justiça emanada de Zeus, e os daimones, que são vigilantes invisíveis dos homens. Para isso, utilizaremos os conceitos do Mesmo e do Outro, encarnados em linhagens diurnas e noturnas, a fim de ressaltar as características associadas a essas figuras - traduzidas, em nível textual, em adjetivos e verbos específicos. Da mesma forma, veremos como elas influenciam no equilíbrio político da cidade.

\section{Palavras-chave}

Proteção; Vigilância; Rei; Daimon; Hesíodo; Política.

\footnotetext{
${ }^{1}$ Profesora Doctora - Universidad de Morón, Morón, Argentina. E-mail: ceciliacolombani@hotmail.com
} 


\section{Introducción}

"Así las cosas, tal vez haya que elegir entre dos caminos: o pensar la mitología a golpes de martillo o trabajar como teórico del 'espíritu humano'”

(Detienne, 1985: 6)

El proyecto del presente trabajo consiste en pensar la perspectiva mítica en Hesíodo como producto del espíritu humano. Fruto privilegiado cuya capacidad nos instala en el marco de una etho-mitho-poiética, una producción de sentido que impacta en una determinada manera de ser.

“ ¿Por qué razón hablar de la mitología es siempre, más o menos explícitamente, hablar griego o a partir de Grecia?" (Detienne, 1985: 7), se pregunta M. Detienne y nos habilita la senda hesiódica con un gesto de coincidencia y convergencia. Este atajo significa instalarse de cara al autor reconociendo su preocupación antropológica, relevando, además, una actitud problematizadora que lo distingue de Homero y lo ubica en un plano que roza la inquietud filosófica.

A las ya conocidas tesis donde Hesíodo aparece como un primer filósofo o, al menos, como un claro exponente de un pensamiento pre-conceptual ${ }^{2}$, queremos aportar una perspectiva por la cual su inserción en el tópos de la primera especulación o, mejor aún, de la incipiente actitud filosófica tiene que ver con su nivel de problematización de la realidad en la cual está inserto, que daría cuenta de una "preocupación histórica", en tanto respuesta a una determinada configuración de época.

En ese brechaase explica la elección de los diferentes tópicos que hemos hecho en el presente trabajo. En primer lugar, la figura del rey justo como contrapartida de los reyes devoradores de regalo, de los dorophagoi, y, en segundo lugar, la de los daimones que surgen luego de la desaparición de los hombres de la raza de oro en el Mito de las Edades. Figuras protectoras inscritas en un linaje luminoso cuya misión consiste en preservar el orden y cuidar de los hombres.

${ }^{2}$ En esta línea, se distingue claramente Olof Gigon y se inscribe mi tesis doctoral "Una aproximación arqueológica al discurso hesiódico desde la lógica del linaje" de (2016), donde he tratado de demostrar la pertinencia y pertenencia filosófica Hesíodo a partir de la consideración del esquema conceptual que sostiene su obra, pensada desde la consolidación arquitectónica de la misma, a partir de la existencia de dos linajes como operadores discursivos y conceptuales. 


\title{
La lógica del linaje. La arquitectura de lo real
}

\author{
“¿De dónde proviene el saber tan plástico que la misma palabra \\ - mitología - designa a la vez las prácticas narrativas, los relatos \\ de todos conocidos y los discursos interpretativos que desde me- \\ diados del siglo XIX hablan de ella según la modalidad y con el \\ tono de una ciencia?
}

(Detienne, 1985: 7)

La novedad hesiódica está, a nuestro entender, en el marco que sirve de arquitectura-andamiaje a su obra, inscrita en lo que llamaremos la lógica del linaje. Consideramos que la idea que Hesíodo representa - sobre finales del siglo VIII-principios del VII a. C. -, radica en el modo de presentar ambos poemas sostenidos por esa lógica como arquitectura discursiva y conceptual.

En ese marco, debemos definir al linaje como un operador discursivo que permite la ordenación del complejo campo, siempre tensionado y polémico, de lo Mismo y de lo Otro; esta resistencia resulta un pilar en el presente trabajo y en la producción hesiódica en general, ya que, según nuestro modelo de instalación, se puede concluir que en ambos poemas, existe una especie de preocupación antropológica, en la que ese territorio tensionado se resuelve en términos de linaje, uno positivo, de matriz diurna y luminosa, y otro negativo, de matriz nocturna y tenebrosa.

Pensemos algunos tópicos que permiten una aproximación significativa a los poemas a partir de la noción de linaje ${ }^{3}$. El linaje como un operador discursivo nos conduce al nivel de la significación y ubica al mito como un lógos explicativo que, a partir del asombro, intenta exponer lo real bajo su lógica imperante. El linaje como un operador discursivo es la noción que posibilita la operación clasificatoria de los campos aludidos, territorializando lo Mismo y lo Otro en tópoi opuestos y complementarios. Está pensado a partir de la plasmación de dos series, una positiva y otra negativa, una diurna y otra nocturna, que operan como ejes discursivo-conceptuales y que albergan en su geografía la representación simbólica de todas las cosas. Con ello permite una clasificación de tipo cosmológica y ético-antropológica. Asimismo, posibilita la ordenación de distintos tipos de realidades: la divina, la cósmica y la humana y ubica a Hesíodo en el plano de un "primer balbuceo filósofo", o, al menos, rodea poéticamente ciertas cuestiones que más tarde serán la tarea misma del quehacer filosófico; de este modo se genera un tránsito complejo entre mito y filosofía.

\footnotetext{
${ }^{3}$ El presente segmento revisita nuestra tesis doctoral, publicada bajo el título Hesíodo. Discurso y Linaje. Una aproximación arqueológica (2016). Introducción.
} 
La lógica del linaje supone comprenderlo como herramienta conceptual e interpretativa para abordar nuestro tópos de instalación, esto es el mito como campo de significaciones rizomáticas. Por lo tanto, nuestro punto de anclaje nos lleva a partir de la existencia de dos campos simbólicos que permiten clasificar, ordenar y re significar la complejidad de lo real. Debemos aceptar también que en la lógica del linaje existe una descendencia diversa, heterogénea, mezcla de luminosidad y tenebrosidad, de claridad y oscuridad, que matiza las dicotomías del esquema, propio de su inscripción en una lógica de la ambigüedad (Detienne, 1986: 15-20).

El diagrama de fuerzas que esos linajes representan, en clara perspectiva agonística, constituye la llave que posibilita la pretensión de Hesíodo, "ambiciones por así decirlo unitarias: esas grandes y complexivas descripciones que, además, al menos en el caso de los dos primeros poemas, representan una visión idealizada: el progreso del mundo consiste en la implantación del orden de Zeus, que garantiza la justicia" (Rodríguez Adrados, 2001: 199).

En este marco, inscrito, además en un proyecto didáctico-moralizador, la lógica del linaje se perfila como operador de sentido y como condición de posibilidad de una arquitectura que ubica las potencias negativas y las positivas en planos diferenciados, en territorios opuestos pero complementarios, lo que imprime un orden lógico a la obra y un hilo de continuidad entre ambos poemas, ya que, más allá de sus diferencias, convergen en una unidad didáctica que prioriza la justicia impuesta y garantizada por Zeus.

Quedan instituidos así en ambos poemas dos territorios conceptuales, definidos en términos de linaje, que permiten clasificar esa totalidad de Ser que incorpora tanto al mundo natural como al humano en un sistema de significación compacto, que da cuenta de la complejidad estructural del mito. Esto no implica, como hemos anticipado, que no aparezcan ambigüedades y mezclas, bifurcaciones y atajos que complejizan el diagrama de fuerzas de esos dos linajes, al tiempo que lo enriquecen simbólicamente. A partir de aquí nos proponemos destacar la figura de los reyes vástagos de Zeus y de los daimones priorizando una lectura que tiene que ver con el cuidado y la protección de los mortales.

\section{El rey. Teogonía, un sentido posible}

“¿Qué es lo que hace que lo que se denomina mito esté habitado o poseído por una necesidad de hablar, por un deseo de saber, por una voluntad de buscar el sentido, la razón del discurso considerado en sí mismo?"

(Detienne, 1985: 11) 
La cita que inaugura el presente segmento nos marca el rumbo ya que de eso se trata; de buscar un sentido posible en el marco de esa lógica que hemos desplegado. La figura del rey, positiva y diurna, refleja una serie de características que nos permiten considerar algunas dimensiones y funciones de la soberanía, de las cuales tomaremos la protección y el cuidado como tópoi de análisis.

En efecto, proponemos pensar la perspectiva de la protección de la justicia y de la verdad como modo de garantizar la función de la soberanía y la cohesión de una aldea y sustraerla de la nefasta influencia de los reyes devoradores de regalos, inscritos en un linaje tenebroso a partir de sus rasgos identitarios; ellos representan una contrafigura y un elemento disruptivo en el marco de lo que proponemos pensar desde la "metáfora médica, figuras de lo Otro que con su modo de administrar la justica determinan un daño manifiesto a la ciudad, a partir del desconocimiento de las rectas sentencias.

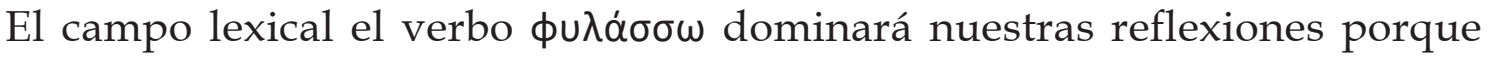
nos orientamos a considerar una función de protección, de cuidado, de vigilancia, de observancia de las leyes, que por venir de Zeus son las mejores. Para comprender el rol de los reyes vástagos de Zeus es necesario apuntar su solidaridad con las Musas ${ }^{4}$. Las Musas son los verdaderos artífices de la inscripción luminosa del rey. Son quienes lo miran al nacer y le otorgan el privilegio real ${ }^{5}$.

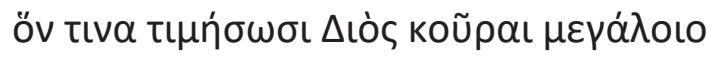

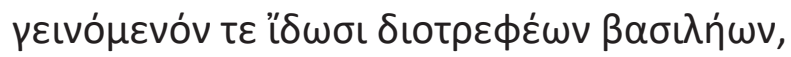

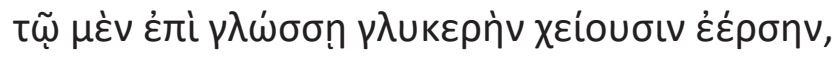

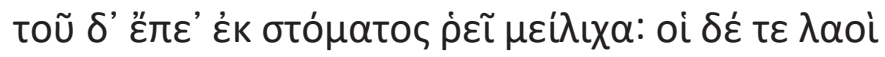

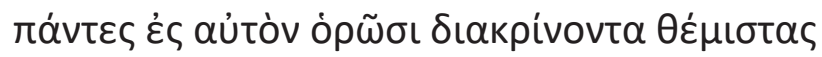

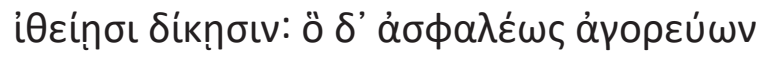

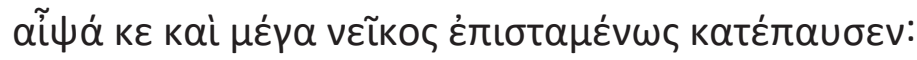

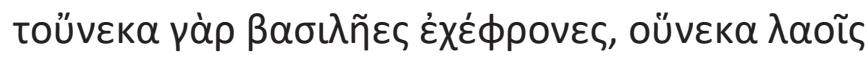

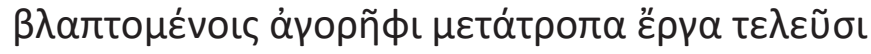

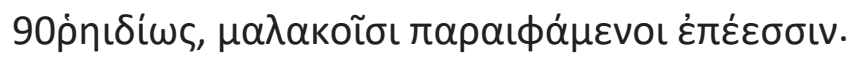

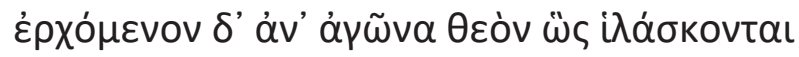

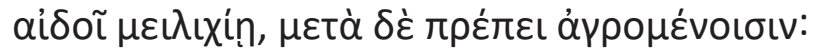

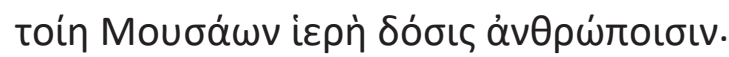

\footnotetext{
4 Sobre la íntima relación entre las bienhabladas hijas de Zeus y los reyes, véase Roth (1976).

${ }^{5}$ Sobre esta función de las Musas, leída desde una dimensión política en tanto productora de efectos, puede verse, Colombani (2016).
} 


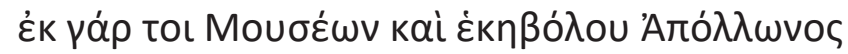

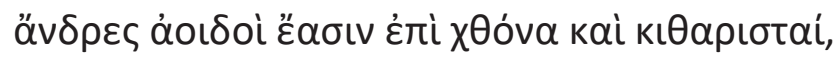

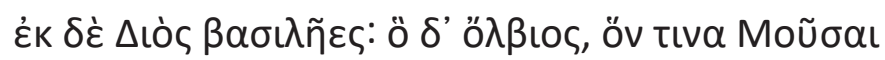

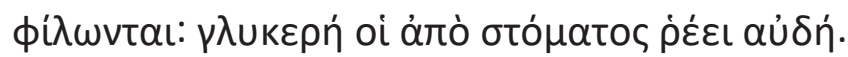

A aquel al cual honran las hijas del gran Zeus

y lo ven nacido de los reyes vástagos de Zeus,

en la lengua dulce rocío le derraman,

y de su boca palabras de miel fluirán; y los hombres

todos contemplan a aquél que discierne leyes

con rectos juicios; pues éste, arengando firmemente, con rapidez y destreza aplaca un gran pleito;

pues por ello los reyes son sensatos, dado que para los hombres dañados, en el ágora cumplirán acciones compensatorias fácilmente, apaciguándolos con tiernas palabras.

Al que llega a la asamblea, como a un dios propician

Con dulce respeto, y entonces sobresale entre los reunidos;

Tal es, de las Musas, el sagrado don para los hombres.

(Teogonía, 81-93).

La relación con el tópico recortado es nítida. El rey se erige como un protector, como un observador, un centinela, $\phi u ́ \lambda \alpha \xi$, de las leyes. Es precisa-

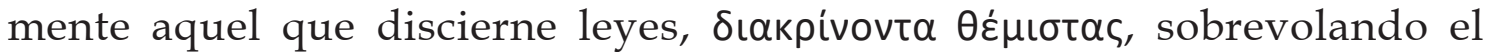

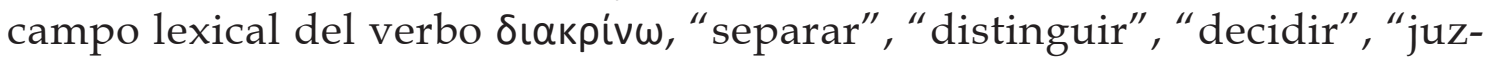

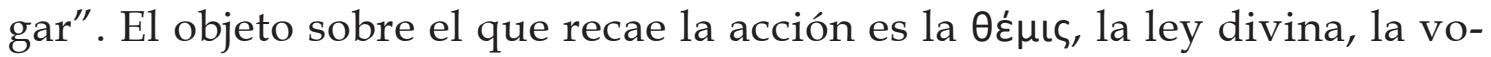
luntad que emana de los dioses como plano alternativo; se trata del decreto que proviene de la divinidad, del más allá. Lo hace desde un poder y un saber que su condición de sujeto privilegiado le confiere y lo ejerce, ade-

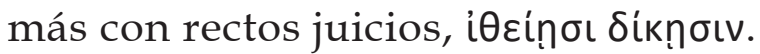

Las marcas de la luminosidad, tanto de la función de soberanía como del ins-

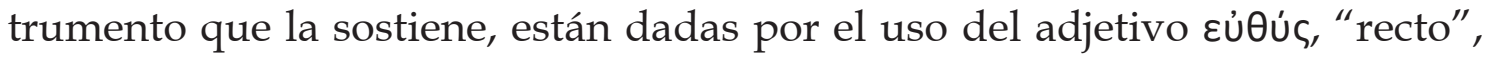
"derecho", "honrado", en clara oposición a lo que será el proceder de los dorophagoi, contra-modelo de la dimensión política.

La única manera de proteger la ley es custodiarla con rectos juicios, îcíñı

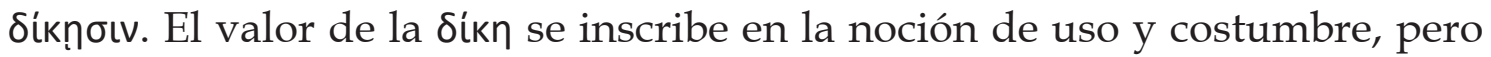
también de juicio, sentencia, decreto y esto abre la dualidad de planos que encierra el mito en su gramática. El rey discierne aquello que desciende de los dioses, quienes habitan un plano que constituye uno de los mundos o razas de los que habla L. Gernet (1981). 
La tarea de custodiar la ley no implica formas violentas de observar el legado divino. El rey administra un tipo de justica y lo hace en consonancia con las marcas que las deliciosas hijas de Zeus le han otorgado; es una figura diurna, de valencia positiva, capaz de brindarle a la ciudad los elementos que la benefician, en clara actitud protectora; por ello, de su boca fluirán palabras de miel,

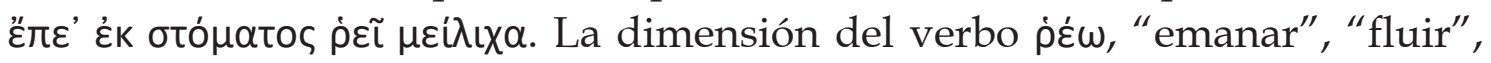
"brotar", da cuenta del modo en que la palabra mana de un sujeto excepcional. Tal cual emergen de la boca de un poeta inspirado, de un maestro de alêtheia.

El mito se vale de estas figuras excepcionales que constituyen la provincia de lo mágico-religioso, tópos intermedio entre los mortales y los Inmortales. El rey es un intermediario de la voluntad de los dioses y sus palabras, દ̌r $\varepsilon$, dan cuenta de esa dualidad de tópoi a la que hiciéramos referencia. El adjetivo $\mu \varepsilon i \lambda \iota x \circ \varsigma$ cierra el cuadro de valencia luminosa: dulce, amable, suave. Tan suaves como las palabras de Nereo, el anciano del mar que constituye, sin duda, el vicario mítico de la función de soberanía.

Ahora bien, hay otro rasgo propio del rey que se asocia a una tarea de protec-

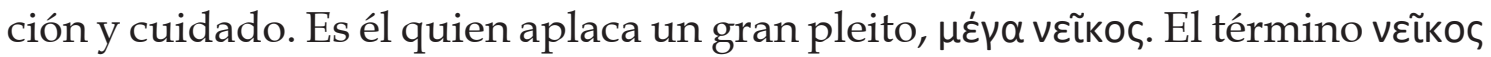
alude a "disputa", "altercado", "riña", "asunto de discordia", significados que nos ubican en la función de protección del orden y la concordia que la comunidad exige para mantener su armonía, esto es, su salud, si volvemos a proponer la metáfora médica como modo de comprender a la comunidad a modo de un cuerpo que obedece a cierta legalidad y cohesión.

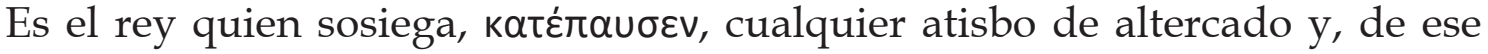

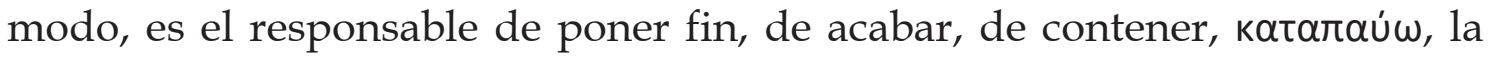
posible y amenazante discordia. La función de protección y custodia exige, sensatez, lo cual ubica a Hesíodo en una intuición de absoluta actualidad que lo convierte en un clásico; por ello se impone un imperativo de una sociedad

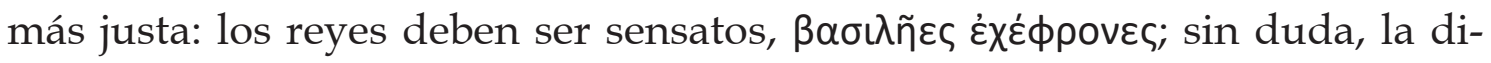

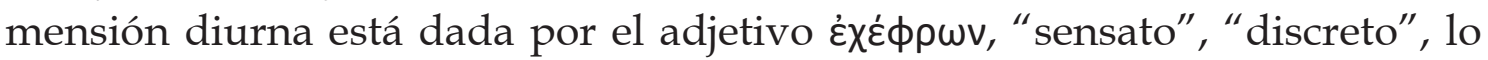
que marca el horizonte de valencia positiva que se une a la dulzura analizada como marcas imprescindibles de la función de vigilancia.

La tarea del rey es doble: velar por la justicia como valor sobre el cual se asienta la salud de la aldea y la cohesión de los hombres que la habitan, y por aquellos que sufren alguna forma de ultraje. Protector, pues, de los injuriados, así se explica que sea quien cumplirá acciones compensatorias,

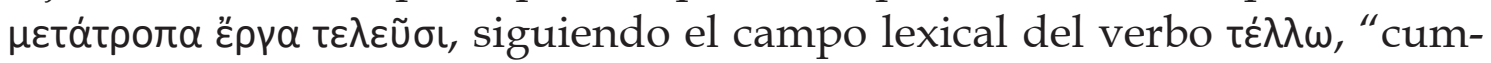
plir", "realizar". Se trata de acciones que retornan compensatoriamente apaciguando las disputas; acciones restauradoras, que se dirigen en gesto 


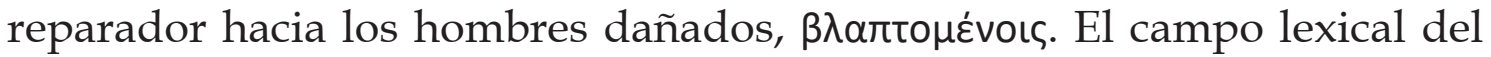
verbo $\beta \lambda \alpha \dot{\pi} \tau \omega$, "dañar", "lesionar", "herir", impacta en el corazón de aquello que se daña, esto es, los hombres que sufren injusticia. La justicia que imparte el rey es terapéutica en la medida en que protege del daño que causa la injusticia como un mal a conjurar.

Una última marca de su figura es el respeto que el rey impone como modelo de autoridad. La presencia de los protectores y de los guardianes que velan por los valores positivos es reverenciada y venerada. Cumplen esa función de custodia del bien que neutraliza toda forma atentatoria del orden y todo eventual retorno a formas asociadas al kháos. En este sentido la función de protección es cosmética, conjurando con su implementación cualquier forma de an-arkhia.

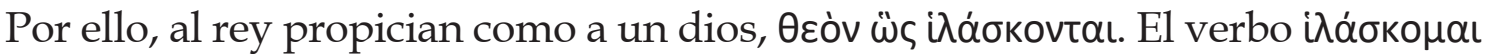
nos marca el rumbo, "apaciguar", "aplacar", "conciliarse", "hacerse propicio". Estamos en presencia de un gesto que homologa, de alguna manera, el estatuto ontológico del rey con el registro de un dios, angostando la natural distancia entre un plano y otro ${ }^{6}$. Tal es la función socio-religiosa del rey como maestro de

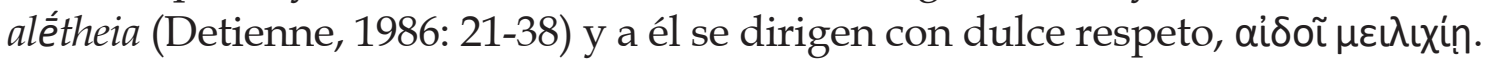

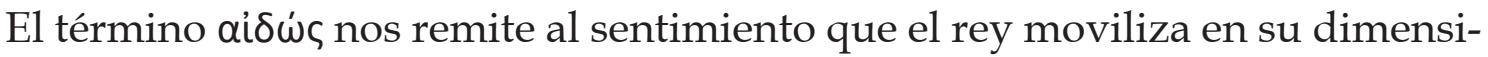
ón protectora, "pudor", "honor", "consideración", "respeto", incluso reverencia, mientras el adjetivo $\mu \varepsilon ı \lambda$ íxıৎ completa el cuadro de valencia diurna, "dulce", "suave", "amable", que atiende a quienes lo invocan. La metáfora de la miel sigue presente en el perfil identitario de quien hace del cuidado del otro su función propia.

\title{
Los daimones. Trabajos y Días, un nuevo horizonte de significación
}

\begin{abstract}
"Una cultura de la palabra entregada con seguridad a la interpretación de los letrados, pero de la que nadie dudaría que tiene más que ver con el oído y la memoria que con la letra y la escritura".
\end{abstract}

(Detienne, 1985: 33)

Un nuevo segmento nos va a permitir ubicarnos en esa cultura de la palabra, en ese territorio del lógos, en el escenario de un relato para ser cuidadosamente

\footnotetext{
${ }^{6}$ Sobre los movimientos de aproximación y asimilación en el universo mítico, véase Colombani (2005).
} 
escuchado como reza la cita que inaugura nuestras reflexiones. El Mito de las Edades constituye, sin duda, una narración emblemática en el marco de aquello que debe ser oído y recordado dentro de la economía general de una palabra didáctica que se dirige a un Tú, encarnado en la figura de Perses, pero que se extiende a la humanidad toda ${ }^{7}$. La letra y la escritura harán más tarde su tarea. Por el momento el lógos hesiódico se alza como una palabra didáctica para ser guardada en el corazón, que da cuenta, a través del mito, de la progresiva decadencia de los hombres a partir de una raza áurea.

Proponemos entonces recalar en Trabajos y Días para relevar una nueva función de protección y cuidado que aparece en el remate de la primera raza que presenta el Mito de las Edades. El Mito de las Edades tematiza la injusticia y sus consecuencias en la evolución de la Humanidad (Finley, 1966: 27) ${ }^{8}$. El problema radica en que esta decadencia antropológica debe inscribirse dentro de la tensión hýbris-sophrosýne. Aunque la sucesión por sí misma, no implica decadencia, tal como sostiene Fontenrose (1978: 8), sí presupone una sucesión dialéctico-estructural entre la desmesura y la medida. No obstante, nuestra posición frente al relato y a la perspectiva de Fontenrose vigoriza la idea de degradación ético-antropológica, entendida como una forma de decadencia, inscrita en el escenario más amplio de una intención didáctica9

El mito de las Edades conduce a Hesíodo por una visión pesimista del futuro inmediato, encaminado peligrosamente a convertirse en el reino de la hýbris, $\mathrm{y}$, por ende, en una amenaza real de carácter a-cósmico. El relato transita por distintas etapas: la Edad de Oro, la Edad de Plata, la Edad de Bronce, la Edad de los Héroes y la Edad de Hierro, en clara alusión a la heterogeneidad de los metales y a su calidad.

El mito como lógos cargado de sentido constituye un intento explicativo de dar cuenta de la progresiva degradación humana, a partir del señorío de la hýbris por sobre la prudencia, en nítida relación política de dominación; en efecto, la desmesura gobierna y la sophrosýne se ve sometida al imperio de la soberbia, lo cual determina una serie de castigos y males, siempre presentes a la hora de delinear el campo del sufrimiento, la fatiga y los pesares, propios del universo antropológico; los hombres progresivamente distanciados de la vieja convivialidad con los dioses se ven abrumados por el peor de los tiempos.

\footnotetext{
7 Sobre el valor del mito como discurso y para un análisis exhaustivo del mito de las cinco razas, puede verse Crubellier (1996).

${ }^{8}$ Mito de probable origen iranio que con el tiempo llegó a Grecia por el Oriente y lo encontramos por primera vez en Hesíodo.

9 Sobre la dimensión didáctica de la poesía hesiódica, véase, Heath (1985)
} 
A su vez, la continuidad del mito de las razas muestra cómo la progresiva decadencia trae aparejada la difícil viabilidad de un kosmos humano, sostenido por la idea de justicia y concordia. La culminación representa, sin duda, la peor desnudez antropológica, la absoluta intemperie de los hombres mortales alcanzada a partir de la degradación. Aidós y Némesis abandonarán a los hombres y se retirarán desde la tierra hasta el Olimpo para vivir junto a los Inmortales; ese retiro dejará a los hombres amargos sufrimientos y, definitivamente, no existirá remedio para tanto dolor y pesar (Trabajos y días, vv. 197-202). Cuando Hesíodo culmina el relato del largo camino de la decadencia y la injusticia, abre un panorama desolador de vínculos transidos por el conflicto ${ }^{10}$.

Hasta este punto tenemos una visión global del desarrollo del mito y las consecuencias del resquebrajamiento de la condición antropológica. No obstante, nuestro interés radica en ubicarnos en la desaparición de la primera raza. Si nos remitimos al inicio del relato, el vínculo entre la raza de oro y la Justicia está atestiguado por el destino que Hesíodo les adjudica a los hombres áureos más allá de la muerte. En efecto, los hombres de esta edad se convierten en daimones epictónicos, en demonios terrenales. Luego de caracterizar positivamente a los hombres de la Edad de Oro, el autor se refiere, como lo hace con cada una de las razas, a su término, dispuesto en cada caso por Zeus. Sepultados bajo la tierra y convertidos en daimones benignos, se transfiguran en protectores de los hombres. Este es el punto al que queremos arribar.

Tal como afirma Rohde, "Los hombres de la raza de oro han muerto ya y siguen viviendo desprendidos de su cuerpo, invisibles, semejantes a los dioses y adornados, por ello mismo, con un nombre privativo de éstos, revistiendo como los dioses mismos en Homero, múltiples formas y figuras, recorriendo las ciudades, vigilando los desafueros y las virtudes de los hombres, semejantes en esto a las almas de los difuntos" (1948: 58). Vayamos al texto.

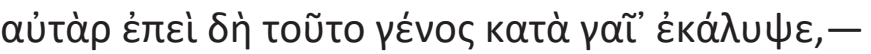

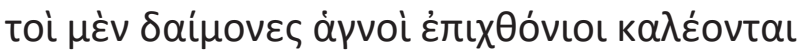

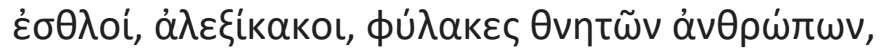

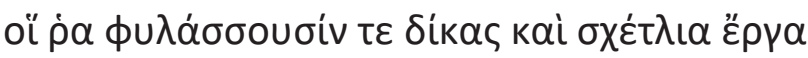

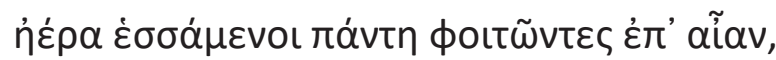

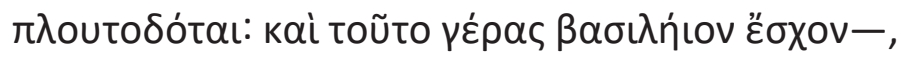

${ }_{10}$ Coincidimos con Neschke (1997: 478) cuando analiza el mito de las razas desde la perspectiva de la exhortación, de la poesía didáctica, pero también, de la consolidación de una moral. 
Después que esta raza bajo tierra él ocultó, éstos son llamados espíritus puros, terrestres, nobles, salvadores del mal, guardianes de los mortales hombres, [que custodian las causas justas y las criminales acciones de bruma vestidos, yendo y viniendo por todas partes sobre la tierra,]

dadores de riquezas; tienen este privilegio real

(Trabajos y Días, 121-126)

Lo primero que registramos es la decisión del Padre de todos los hombres y

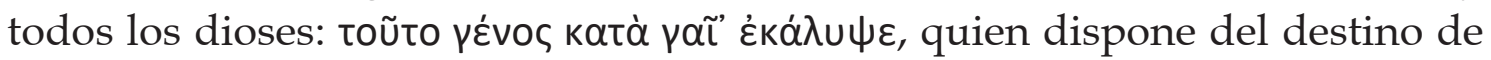
estos primeros hombres, como lo hará también con el de las demás razas. El

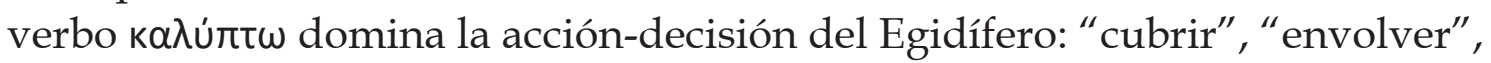
"ocultar". La metáfora espacial, katà yoũ, bajo la tierra, ubica a los daimones en un lugar de invisibilidad. La suma de marcas identitarias despliega su inscripción en un linaje luminoso, de valencia positiva, que complementará estructuralmente la función protectora y benefactora.

Los espíritus son puros, àyvoi, inocentes, pero también sagrados, santos. El adjetivo refuerza la familiaridad de los daimones con lo divino, su parentesco estructural que los convierte en aliados estratégicos de la divinidad para cola-

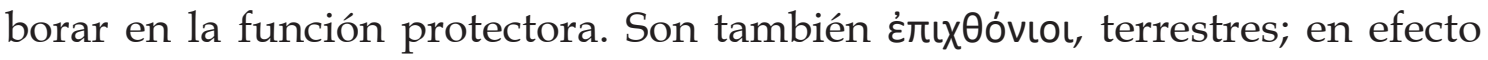
son entidades que viven en la tierra, terrenales, y esa superficie es la que los alberga para cumplir su misión de cuidado.

La próxima marca es definitoria para nuestro atajo interpretativo. Son salva-

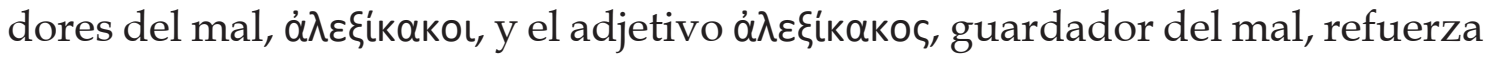
la metáfora salvífica. Los daimones cumplen la función de ser protectores, defensores de los hombres contra el mal. La imagen sobrevuela el campo lexical del verbo ả $\lambda \dot{\varepsilon} \xi \omega$, "apartar", " proteger”, " asistir", " defender”. Este es el campo simbólico de la función protectora. Apartan el mal para defender a los morta-

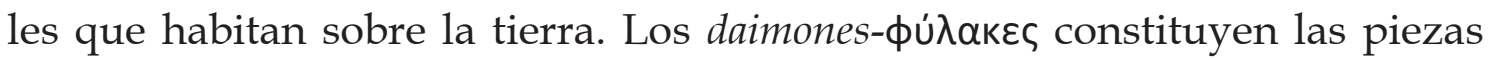
imprescindibles del dispositivo político de protección que limpia la maldad, retornando así la metáfora medica que utilizáramos.

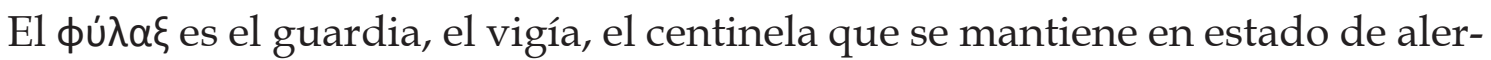
ta para proteger y custodiar el orden. La clave es territorializar al mal, fijarlo, acorralarlo para que su presencia no destruya la tarea ordenadora del Padre, garante del orden y de la justicia. En este sentido y, en el marco agonístico que implica la tensión entre lo bueno y lo malo, los daimones se convierten en aliados estratégicos de Zeus en la tarea de preservar el kósmos. Se constituyen, de algún modo, en funcionarios de la soberanía. 
Ahora bien, pensemos qué es exactamente lo que vigilan. Aparece en este punto la tensión binaria que Hesíodo suele presentar.

Son ellos los que custodian las causas justas y las acciones criminales,

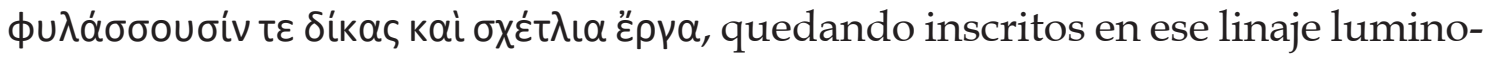
so que la arquitectura hesiódica reserva para las figuras positivas que velan por el orden y la bondad. El sustantivo díkn no solo alude a la noción de justicia, sino también a la idea de causa, de costumbre, de manera de ser u obrar.

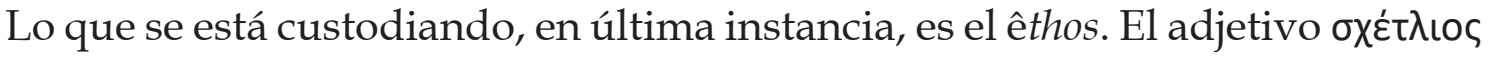
contrapone la estructura en espejo, abriendo un cuadro de valencia negativa: "insolente", "criminal", "perverso", "abominable", son algunas acepciones del término.

El modo de moverse de estas divinidades intermedias que en Hesíodo revisten un signo positivo, pero que, en otras tradiciones pueden tener signo opuesto, está dado por el matiz del verbo фoıtw̃, ir y venir constantemente, andar de un lado a otro; se trasladan cubriendo la totalidad del territorio, estableciéndose sobre la tierra, غ̇л' aĩav, sin dejar parte alguna sin custodia. La imagen evoca un dispositivo de vigilancia total, que llega a todos los intersticios a vigilar y controlar.

El dispositivo juega con la invisibilidad como forma de funcionamiento. Los

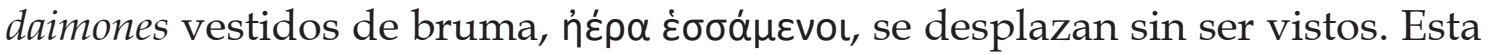
condición facilita la tarea de control porque la bruma o la niebla, áń esa circunstancia privilegiada para el ejercicio de la vigilancia de ver sin ser visto. Especie de panóptico ${ }^{11}$ arcaico al servicio de guardar las buenas maneras y acciones que mantienen el kósmos en orden y salvaguarda de los elementos asociados al mal. Su matriz diurna se intensifica por su condición de dadores de riqueza, $\pi \lambda$ outoסótal, herederos directos de aquellos hombres de la raza áurea en la que la riqueza, $\pi \lambda$ ○õ̃oৎ, cumplía un papel preponderante. La línea de sucesión del linaje inscribe a los daimones en un punto de contacto y similitud con la divinidad que es, habitualmente, dadora de riquezas.

En la misma tradición se comprende el final de los versos; los protectores "tie-

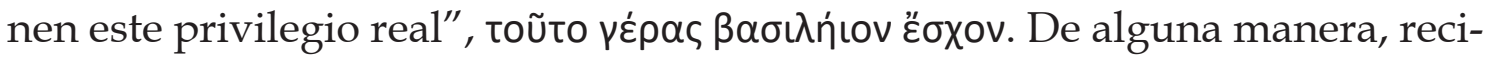
ben la misma prerrogativa que han recibido los hombres áureos: la familiaridad con lo divino se expresa en términos de privilegio. El vocablo үépaৎ resulta decisivo para inteligir el contacto entre ambos planos: presente de ho-

${ }^{11}$ Foucault en Vigilar y Castigar describe la arquitectura del panóptico como dispositivo emblemático de las sociedades de control. Se trata de una torre que posee un sistema de aberturas que invierte la pareja ver-ser visto. Aquel que vigila puede observar la totalidad, sin ser él mismo visto. El control se vuelve así menos material e invisible. 
nor, distinción, privilegio, recompensa. Como en tantos otros aspectos que el mito refleja en su relato ancestral, el gesto se inscribe en la lógica del don que materializa la elección, por parte de los dioses, de ciertas entidades que son elegidas desde su voluntad irrevocable.

Ese toque divino establece las líneas de continuidad genealógica y hace de un héroe, por ejemplo, el igual a un dios. Siempre debe existir un elemento que garantice la continuidad entre un tópos y otro.

\section{Conclusiones}

"Historias contadas desde siempre e incesantemente repetidas; todos las han oído y las conservan en la memoria".

(Detienne, 1985: 109)

El proyecto de nuestro trabajo consistió en pensar la dimensión del mito en Hesíodo como producto del espíritu humano, a partir de lo que podemos considerar una etho-mito- poiética en tanto modo de instalación antropológica, y en reflexionar sobre la capacidad del mito como operador de sentido. Hesíodo constituye, a nuestro entender, un primer filósofo o, al menos, un nítido exponente de un pensamiento pre-filosófico, que instituye el complejo campo entre mito y filosofía, en un terreno que nos gusta retratar desde la imagen de las "sendas embrolladas", aludiendo a la expresión foucaultiana (Foucault, 1979). Desde esta posición, quisimos recuperar una cierta actitud filosófica inscrita en su preocupación por la realidad histórica en la cual está inserto, de cara a un futuro cargado de tenebrosidad y reconociendo una inquietud por una sabiduría de vida y los rasgos de un pensamiento arcaico de marcado vigor y proyección ulterior (Rowe, 1983).

Recorrimos también lo que, según nuestro criterio, constituye la novedad hesiódica, poniendo de relieve la arquitectura-andamiaje que sostiene y da continuidad a su obra, enmarcada en la lógica del linaje. A partir de allí propusimos el tratamiento de dos figuras: la de los reyes vástagos de Zeus y la de los daimones que cierran la edad áurea; ambas se encuentran inscritas en un linaje diurno, de valencia positiva y que permiten pensar en una posibilidad de optimismo frente al estado de las cosas.

La figura del rey nos mostró un plexo de marcas identitarias recobradas a partir de la utilización de la herramienta filosófico-filológica que nos permitió considerar la función de soberanía como la dimensión emblemática en la que confluyen dos nociones: la protección y el cuidado. 
En un segundo momento, hicimos pie en el Mito de las Edades para captar la visión pesimista del futuro inmediato, a partir de la amenaza de carácter a-cósmico que encauza la progresiva degradación antropológica.

En este marco, de manifiesto registro patético y dentro del esquema agonístico que inscribe la tensión mesura-desmesura a lo largo de la obra, analizamos las marcas de los daimones convertidos en aliados políticos de Zeus en la ardua tarea de preservar el kósmos, a partir de su dimensión de garante de la justicia. Una vez más, revisitamos los tópicos recortados y ambos, la protección y el cuidado, analizados bajo la responsabilidad de los daimones, marcaron la recomendación del control, la observancia y la mirada atenta como herramientas imprescindibles para la institución y conservación del orden.

\section{Bibliografía}

COLOMBANI, María Cecilia. Hesíodo. Una introducción crítica. Buenos Aires: Santiago Arcos, 2005.

. Hesíodo. Discurso y Linaje. Una aproximación arqueológica. Mar del Plata: EUDEM, 2016.

CRUBELLIER, Michel. "Le mythe comme discours Le récit des cinq races humaines dans Les Travaux et Les Jours". Le métier du mythe. Lectures París: Presse Universitaires du Septentrion, Vol. 16, 1996, pp. 435-463.

DETIENNE, Marcel. La invención de la mitología. Barcelona: Península, 1985.

DETIENNE, M. Los maestros de verdad en la Grecia Arcaica. Madrid: Taurus, 1986.

FINLEY, Moses I. El mundo de Odiseo. México: Fondo de Cultura Económica, 1966.

FONTENROSE, Joseph. "Work, justice, and Hesiod's five ages". Classical Philology, University Chicago Press Vol. LXIX, N 1, 1974, pp. 1-16.

FOUCAULT, Michel. "Nietzsche, la historia, la genealogía" Ídem Microfísica del poder. Barcelona: Ediciones La Piqueta, 1979.

. El orden del discurso. Barcelona: Tusquets, 1983.

. Vigilar y Castigar. Buenos Aires: Siglo XXI, 1989.

GERNET, Louis. Antropología de la Grecia Antigua. Madrid: Taurus, 1981. 
GIGON, Olof. Problemas fundamentales de la filosofía griega. Buenos Aires: Compañía General Fabril Argentina, 1962.

. Los orígenes de la filosofía griega. Buenos Aires: Gredos, 1985.

HEATH, Malcolm. "Hesiod's Didactic Poetry". The Classical Quarterly, New Series, Cambridge University Press, Vol. 35, n² 2, 1985, pp. 245-263.

HESIOD. Theogony. Works and Days. Testimonia. Most, G. W. (editor y traductor). London: Loeb Classical Library, Harvard University Press, 2006.

HESÍODO. Obras y fragmentos. Madrid: Gredos, 2000.

LIÑARES, Lucía. Hesíodo Teogonía, Trabajos y Días. Edición bilingüe, Buenos Aires: Losada, 2005.

NESCHKE, Ada. "Dikè. La philosophie poétique du droit dans le "mythe des races" d'Hésiode". Le métier du mythe. Lectures d'Hésiode, sous Paris: Presse Universitaires du Septentrion, Vol. 16, 1993, pp. 465-478.

RODRÍGUEZ ADRADOS, Francisco. “La composición de los poemas hesiódicos”. EMÉRITA, Revista de Lingüística y Filología Clásica (EM), LXIX 2, 2001, pp. 197-223.

ROHDE, Erwin. Psique. La idea del alma y la inmortalidad entre los griegos. México: Fondo de Cultura Económica, 1948.

ROTH, Catharine P. "Kings and Muses in Hesiod's 'Theogony". Transactions of the American Philological Association (1974), The John Hopkins University Press, Vol. 106, 1976, pp. 331-338.

ROWE, Christopher J. "Archaic Thought' in Hesiod". The Journal of Hellenic Studies, The Society for the Promotion of Hellenic Studies, Vol. 103, 1983, pp. 124-135.

VIANELLO DE CÓRDOVA, Paola. Hesíodo Teogonía. México: Universidad Nacional Autónoma de México, 1978. 